Veraart, Albert. 1976. "Geschichte des wissenschaftlichen Nachlasses Philosophical Analysis of Language, Amsterdam: John Benjamins (1987), 205-227.

Gottlob Freges und seiner Edition: Mit einem Katalog des ursprünglichen Bestands der nachgelassenen Schriften Freges”. Schirn 1976. I. 49-106.

Weyl, Hermann. 1966. Philosophie der Mathematik und Naturwissenschaft. München \& Wien: Oldenbourg.

Windelband, Wilhelm. 1884. Präludien: Aufsätze und Reden zur Philosophie und ihrer Geschichte. 2 vols. Tübingen: Mohr.

- - 1892. Lehrbuch der Geschichte der Philosophie. 15th ed. revised and enlarged by Heinz Heimsoeth. (Repr. of the 13th. ed. of 1935. Tübingen: J.C.B. Mohr, 1980.)

Wundt, Wilhelm, 1880-83. Logik: Eine Untersuchung der Prinzipien der Erkenntnis und der Methoden wissenschaftlicher Forschung. Vol. I: Erkenntnislehre. Vol. II: Methodenlehre. Stuttgart: F. Enke. (2nd revised ed. 1893, 1894-95.)

Ziehen, Theodor. 1920. Lehrbuch der Logik auf positivistischer Grundlage mit Berücksichtigung der Geschichte der Logik. Bonn: A. Marcus/E. Weber. (Repr., Berlin \& New York: Walter de Gruyter, 1974.)

Zweig, Arnulf. 1967. "Sigwart, Christoph". The Encyclopedia of Philosophy ed. by Paul Edwards, vol. VII, 441-442. New York: Macmillan.

\section{HUSSERL, LANGUAGE, AND THE ONTOLOGY OF THE ACT}

\author{
BARRY SMITH ${ }^{1}$ \\ University of Manchester
}

\begin{abstract}
The objection that we are attempting here a restitution of the Aristotelian-scholastic logic, on whose inferior value history has pronounced judgment, should not perturb us. Perhaps it may yet turn out that the discipline in question is by no means so narrow in scope and so poor in profound problems as it is reproached with being. Perhaps traditional logic was merely a highly imperfect and dim realization of the idea of pure logic, but none the less competent and worthy of respect as a first beginning (Husserl, "Prolegomena to Pure Logic", § 13).
\end{abstract}

\section{Tasks of an Ontology of Language}

The term 'ontology' has played a role in recent discussions of language and linguistics almost exclusively in connection with the problem of the so-called 'ontological commitments' of a linguistic theory. In the present paper however the term 'ontology' is used in a way that is at once more modest and more ambitious. It is more modest, because ontology will be understood not as a higher-order investigation of e.g. linguistic theories, but as a discipline having as its subject-matter the objects themselves, which such theories investigate. It is more ambitious, because it will extend beyond 'language' as narrowly conceived to include also, for example (in conformity with an older tradition of universal grammar), the acts and actions of language-using subjects. Indeed we may say that the ontology of language is concerned precisely with the relations between uses of language, both overt and covert, and other entities, whether in the world or in the mind of the subject.

A first survey of the sorts of relations which might come into question for such an ontology would include:

(a) relations between a referring use of an expression and its object, ${ }^{2}$ 
(b) relations between the use of a (true) sentence and that in the world which makes it true, ${ }^{3}$

(c) relations between a used predicate and the object or objects of which it is predicated, and also, at least in certain cases, between this object and those of its parts and moments in virtue of which the predicate holds,

(d) relations among uses of language themselves, for example anaphoric relations, relations between those events which are referring and predicating uses of expressions, relations between successive uses of sentences in higher-order structures such as narratives, arguments, conversations, and so on.

I shall have something to say about all of these species of examples in what follows. My main concern, however, will be with the ways in which uses of language are bound up with mental acts. Thus for example I shall be concerned with:

(e) relations between mental acts on the one hand and underlying mental states (attitudes, beliefs), on the other,

(f) relations between my acts and states and those associated uses of language which are overt actions on my part, for example actions of promising or of asking questions,

(g) relations between my mental acts and states and the overt actions (including utterances) of other subjects with whom I come into contact (relations of understanding, of communication).

It is remarkable how few analytic philosophers have attempted to describe any of these relations in more than merely metaphorical terms as if language, narrowly conceived as a system of abstract types, would exist in splendid isolation from mental and other sorts of structure. Proponents of causal and historical theories of names have taken some initial steps in connection with (a), but their accounts are too narrowly causal, and often little more than promissory notes. Advocates of the semantics of natural language have done some work in the areas of (c) and (d), but the analytic philosopher's understanding of the objectpredicate relation has advanced not at all since Frege conceived his peculiar function-argument interpretation. Moreover, work on the interrelations between successive uses of language, at least on the part of the more philosophically minded theorists of language, has been concentrated overwhelmingly on those cases which can be pressed within the schemata of one or other orthodox system of logic. Some work, especially that associated with the names of Grice, Schiffer, Strawson, has been done by analytic philosophers on the interconnections between language and associated mental acts, and proponents of speech act(ion) theory have made some headway in particular with parts of $(f)$ and $(g)$, but their accounts do not mesh at all with any worked-out ontology: they resolve accounts do not mesh at all with any we certain logical relations between sentences (promise $\mathrm{S}$ is felicitous iff...), and throw little light on how speech act(ion)s are $\mathrm{S}$ is felicitous iff...), and the be with those mental events which are acts and those mental states which are beliefs, convictions, desires, etc.

There is one philosophical tradition, however, which did concern itself precisely with the whole range of relations of the given sort. It is the tradition which began with the work of Franz Brentano (1838-1917) and his students, above all Alexius Meinong (1853-1920), Carl Stumpf (18481936) and Anton Marty (1847-1914), and reached its high-point in the 1936) and Anton Investigations of Edmund Husserl (1859-1938). This tradition Logical Investigations of Edmund Husserl (1859-1938). This trasts such as Johannes Daubert (1877-1947) and Adolf Reinach (1883-1917) and in Johannes Daubert (1877-1947) and Ad by such thinkers as Roman Jakobson (1896-1983) and Karl Bühler (1879-1964). The present essay is a brief survey of the philosophical work on language by the members of this tradition, together with a comparison of the results of their work with other, competing approaches.

\section{Species and Generality}

Of central importance for what follows will be the theory of dependence-relations set forth, in germ, in Husserl's third Logical Investigation and anticipated by Brentano in his lectures of 1887-91 on Deskription and anticipated by Brentan in the various different relations mentioned above can be understood in the terms of this ontology, in a way that is at once elegant and economical. Before presenting Husserl's views on dependence, however, it will be useful to make some more general remarks penden subject of generality: for the opposition between species and instance, between what is general and what is particular, will turn out to be fundamental to the entire project of a theory of language in the Husserlian sense.

Imagine that we are called upon to look at the world as a zoologist, or a phonologist, or a warehouse manager, or a fingerprint expert might. We notice very soon that some features of the world are constant, while others vary. It is important not to import philosophical simplifications - of either what one might call the Platonistic or the nomiplifications - of eithe description of this fact. Constancy occurs not benalist sort - into the description of thidual realia, abstract essences which cause there are, in addition to ind in different objects. And nor does it some not further explicable propensity of subjects to 
use general terms in certain ways. Constancy occurs, rather - or at least this is the core of the Brentano-Husserl view - because objects have real parts or moments ('respects') which stand to each other in relations of perfect similarity. ${ }^{5}$ These may be moments of the most simple sort, for example moments of colour or taste. (The sentence 'Hans's arm is the same colour as Bruno's leg' is made true by the perfect similarity between the individual colour-moments inhering in their respective limbs.) Or they may be more complex, higher-order structures founded upon these. (The sentence 'these two sequences of whistles are performances/instances of the same melody' is made true by a relation of perfect similarity between certain Gestalt-qualities inhering in the respective quantities of sound-material.)

In virtue of such relations of perfect similarity, which may obtain on different levels, objects are gathered into classes of actual and possible similars called by Husserl 'species'. Such species are not additional abstract entities. Rather, talk of species is to be cashed out in terms of relations of similarity between certain real parts and moments of entities on the level of what is concrete and contingent.

This deflationary interpretation of Husserl's thinking on species and generality is controversial. The issue is confused by the fact that one important aim of the Logical Investigations was to attack psychologism in logic, and particularly in volume I of the work - the "Prolegomena to Pure Logic" - where Husserl is concerned to dramatise the inadequacies of psychologism, he seems to put forward a Platonistic view of the nature of species as 'ideal singulars', a view which contrasts, to some extent, with the similarity view sketched above. When we look more carefully at Husserl's use of the species concept in the body of the work, however, then it becomes clear that his motives for introducing talk of species are not those of the Platonist. Indeed he pours scorn on Platonism in the traditional sense - on the view that species are real entities (LU II § 7) - and he spends little time reflecting on species themselves or on their ontological properties. $\mathrm{He}$ is much rather concerned with the instances of species and with the problem of finding a means of doing justice to the manifold sorts of constancy or regularity and to the manifold sorts of law-governed connection that we encounter among such instances, both in the world and in our mental acts.

Why, then, did Husserl utilise this terminology of species at all? This was, I think, for two reasons. First, it is the basis of Husserl's theory of logic (a) that logic is a science having its own specific subject-matter, and (b) that this subject-matter should not be a matter of empirically occurring instances but of entities somehow outside the world of what happens and is the case. Logic is a science of thinkings, inferrings, rea- sonings in specie: it is a science of the relations between species of these given sorts (see e.g. LU II § 2). Second, it was important to Husserl's theory that the real relations of similarity amongst logical entities do not occur as it were at random, but that they themselves exhibit a certain order. In particular, they manifest a hierarchical structure, so that species are included in other species at higher levels of generality, the corresponding predicates being organised into trees of determinables and determinates. This is a property of universals that was taken for granted by logicians of a more traditional bent, from Aristotle and Porphyry to W.E. Johnson. ${ }^{6}$

\section{Husserl's Theory of Dependence and its Linguistic Applications}

We are now in a position where we can say something about Husserl's theory of dependence, which is all of a piece with his theory of species. For Husserl recognised that there are, in addition to the vertical (inclusion) relations between species, certain sorts of lateral relations, sharing with them important modal properties. Examples of the vertical relations would be:

every instance of the species red is also an instance of the species colour; every instance of the species mammal is also an instance of the species animal; every instance of the species judgment is also an instance of the species mental act.

Such relations involve moving from one species to another along given branches of a single species-tree. They can be more or less satisfactorily captured by means of the familiar inclusion relation of standard set theory. Lateral relations, in contrast, involve moving from one branch to another, or perhaps even moving to a wholly different tree. Such relations, even when conceived merely extensionally, fall outside standard set theory or any of its more usual extensions. Examples of such lateral relations are:

no instance of the species funeral occurs, without a prior and associated instance of the species death:

no instance of the species colour exists, without a simultaneous and associated instance of the species visual extension;

no instance of the species phoneme is also an instance of the species edible thing:

no instance of the species red coincides with (occupies the same spatio-temporal area as) an instance of the species green.

These relations are, in Husserl's terminology, relations of dependence and of necessary exclusion or incompatibility. Such relations are of course in a certain sense trivial (no less trivial, indeed, than the vertical or analytic relations which are captured in the arbor porphyriana of the 
traditional sort). This does not mean, however, that they can be ignored; and nor, either, does it mean that there is not a great advantage to be derived in embedding them within a theoretical framework within which their status can be clarified and their character of apparent arbitrariness removed. ${ }^{7}$ The theory of such relations has indeed been shown, in as yet unpublished work by Kit Fine, to yield a mathematical framework of some elegance and complexity, though it would take us too far from our main concerns to develop the details of the theory here. ${ }^{8}$ Suffice it to point out that Husserl distinguishes between one-sided and reciprocal dependence, e.g. between the one-sided dependence of an instance of the species musical tone on an instance of the species temporal duration, and the three-sided mutual dependence of instances of the species pitch, timbre and loudness within a given tone.

Such $\mathrm{n}$-fold dependence relations correspond to $\mathrm{n}$-fold dimensions of variation in the space of objects governed by the relations in question. Husserl's own fourth Investigation is in fact an application of the theory of dependence to the relations structuring the space of meaningful uses of language. Uses of language can be divided, at different levels, into (relatively) dependent and (relatively) independent, in a way that can be shown to generate a categorial order of types of such uses (i.e. of the various 'parts of speech'). Thus Husserl's work on the laws governing dependent and independent meanings influenced the development of categorial grammar by Leśniewski and Ajdukiewicz (see Smith \& Mulligan $1982, \S 5)$, and the idea of a grammatical theory built up on the basis of a theory of the dependence relations between parts of sentences has since been developed formally by linguists such as Mel'čuk and Hudson as alternatives to grammars of the more familiar transformational sort. ${ }^{9}$ All of these grammars, however, exploit theoretical resources weaker than those available to Husserl, since they employ exclusively the notion of unilateral dependence or its equivalents. The idea of a dependence or categorial grammar utilising also relations of mutual dependence is currently in process of investigation by $\mathrm{W}$. Haas.

Husserl's theory of dependence was employed also by the linguist Roman Jakobson, above all in his work on distinctive features in phonology and on implicational universals of language acquisition (see Holenstein 1976). But its most thorough-going application was carried out by the Munich phenomenologist Adolf Reinach in his "Die apriorischen Grundlagen des bürgerlichen Rechts" of 1913. Reinach's work is, notwithstanding its somewhat misleading title, an investigation of the ontology of those complex structures which are actions of promising, commanding, forgiving, questioning, and so on, structures which straddle the borderlines not only of linguistics and psychology but also of juris- prudence and the theory of action. A good case can indeed be made for the claim that Reinach, already in 1913, had set forth the essential elements of what later came to be called the theory of speech acts. His work even contains a discussion of the various 'infelicities' to which speech acts can be subjected, not, however, in terms of any quasi-logical 'conditions of satisfaction', but rather in terms of a theory of the various possible sorts of ontological modifications which structures involving speech acts may undergo, a theory which is then applied also to throw light on the ways in which such structures may be affected by determinations of the positive law. ${ }^{10}$

\section{Acts and their Distinctive Features}

It is Husserl's own application of his theory of species and dependence to the problem of linguistic meaning which will engage our attention for the remainder of this paper. Husserl's theory of meaning in the Logical Investigations is an act-based theory. Language is seen as having meaning only to the extent that there are subjects who bestow meanings upon specific expressions in specific sorts of mental acts. ${ }^{11}$ Before we can present this theory, however, we shall need to say something about the internal structures of mental acts in general.

Internal structure is captured by recognising dependence relations amongst really existing parts. Thus every act, according to Husserl, manifests the three distinctive features of quality, matter and intuitive actcontent. These three features stand in a three-sided dependence relation: no instance of the species act quality can exist except in a larger whole in which it is bound up with instances of the species matter and intuitive content, and these in turn cannot exist without each other and without an instance of the species act quality: The space of acts is in this sense three-dimensional. ${ }^{12}$

The quality of an act is the way in which the act is intentionally directed towards its object: categorially or hypothetically, in perception or in imagination, and so on. The matter of an act is that feature of the act in virtue of which its object is given as an $F$ or as a $G$ : as a flower or as a rose, as a noise or as an explosion, as inviting or as threatening, and so on. ${ }^{13}$ And the intuitive content (which Husserl also refers to as 'hyletic data') is that feature which embraces all that is sensuously given in the act, including, for an act of language-use, sensuous signs (words, or such constituents of thoughts as correspond to words).

What does Husserl mean when he says that an act exhibits these three distinctive features? Consider an act of seeing an apple. This act can be 
imagined as varying in (at least) three different ways: I can imagine myself turning away from the apple and remembering exactly what I saw. My act of remembering then has a matter and intuitive content that are similar to those of the perceptual act on which it is founded. The quality of the act of memory, however, is quite different from that of the perception that precedes it. Similarly, I can imagine myself seeing the apple, but in such a way that what I (think I) see is a pear. Here quality and intuitive content are the same, but the matter is different. Or I can imagine myself seeing the apple e.g. under different lighting conditions. Quality and matter are thereby fixed, while intuitive content varies. Or again: suppose that I make two different assertions, one after the other. Here the qualities involved in my two acts are the same, the matters differ. If, on the other hand, I assert $p$ and then subsequently wonder whether $p$, then the matters are the same, the qualities differ.

Quality, matter and intuitive content can themselves in turn be internally complex. Thus consider the intuitive content of an act of perception of a musical tone. Here we discover at least three abstractly distinguishable parts of the content, corresponding to the three abstractly distinguishable features of the tone - its pitch, timbre and loudness mentioned above. Just as these features reflect dimensions of variation in the tone, so the corresponding parts of the intuitive content reflect dimensions of variation in the act. And it is easy to see that, as with the tone, so also with the act, each part or feature is such that, as a matter of necessity, it cannot exist in isolation from the others.

Importantly, this claim is not affected by the fact that there are many of us who hear tones but do not know that we thereby also hear, say, timbre (who do not know what timbre is). For the existence of an act part is not to be confused with its being noticed or recognised: the fact that a subject is not able to identify, discriminate or name parts, moments or features of his acts is irrelevant to the question whether or not they are there. ${ }^{14}$. If Fritz can hear a difference between a violin tone and an oboe tone of the same pitch and intensity, then his act contains a timbre-component. He needs only to hear the difference, not say or recognise what it consists in. As we shall see, this is one dimension of the ontology of the act - we shall encounter others below - to which phenomenology would seem to be inadequate. For the dimensions of acts, like the dimensions of musical tones, are in some sense objective; they are independent of what an individual or a society notices, or of what a natural language expresses.

It has been assumed in all of the above that mental acts are internally complex spatio-temporal entities whose features instantiate species (in the sense of our discussion in $\S 2$ ). This holds in particular of acts of be- stowing meaning upon expressions, which are simply those acts which do the job of supplying objects for the expressions in question. These objects are things, events, processes, etc., in the case of nominal expressions, states of affairs in the case of judgments. Such 'objectifying acts', too, manifest the three dimensions of matter, quality and intuitive content, a fact which Husserl exploits to produce his own, quite specific account of linguistic meaning. He argues, in fact, that linguistic meanings are, just, certain species: they are, roughly, the species of those acts which are acts of meaning-bestowal. ${ }^{15}$ Two immediate advantages of this theory can be pointed out immediately. The first is trivial, relating to an ambiguity in our use of the verb 'express'. Thus on the one hand we are accustomed to saying that uses of language express their (ideal, abstract) meanings, and on the other hand that such uses express certain acts on the part of the language-using subject. This ambiguity is not a matter of accident, on Husserl's theory; it flows directly from the fact that act and meaning relate to each other as instance to species. The second advantage relates to uses of language in communication. If Erna understands what Hans says, then whilst Hans's and Erna's thoughts are numerically distinct internally complex events, they are yet such that, in virtue of the similarity of their matters (and therefore also of their objects), they are instances of one and the same species (at some point on the meaning tree). When two interlocutors successfully communicate we can describe what this success consists in by appealing to this identity of species, that is, to the existence of a certain constancy or regularity in the space of mental acts of the relevant community of language-using subjects.

\section{The Place of Mental Acts}

Now whilst Brentano and Husserl have shown that an ontological theory can be developed which can do justice to the structures of acts, it remains the case - as is unavoidable, given the nature of the subjectmatter - that such an ontology is both problematic and highly complex. There remains, therefore, a certain temptation to ignore acts and to look instead at linguistic expressions. Such expressions are after all obviously and cleanly separable from each other and - in non-Cretan cases - from associated referents. They also have the advantage of being publicly accessible. Further, many of the structures of acts are manifested also in the kinds of things we say, and thus the linguistic study of descriptions or reports of mental acts may well have light to throw on such structures, were its advocates once freed of the tendency to read in- 
to the domain of acts structural simplifications derived from the spheres of logic or language. ${ }^{16}$

More often, however, the philosophical investigation of language has been held to enable the by-passing of theoretical concern with mental acts through the study of those overt actions in which language gets used. As is shown already by the work of Reinach, there is much in the actioncentred approach which makes it congenial to the ontological position defended here. It is an approach which rejects the conception of language as a matter of abstract types, turning away from abstract models in general and paying attention instead to the real events, scattered through time and space, in which language gets used. Modern philosophers of action argue further, however, that the sympathetic treatment of such real events makes the appeal to mental acts unnecessary.

It was Ludwig Wittgenstein (1889-1951), in particular, who had the aim of dislodging theoretical or cognitive acts from the preeminence they have enjoyed in post-Cartesian philosophy. ${ }^{17}$ Deeper than any agreement in judgment, Wittgenstein insists, is agreement in habits and traditions. If mental acts exist at all, then they are a derivative phenomenon, owing whatever status they might have to their manifestations in overt behaviour.

It is indeed tempting to agree with Wittgenstein that the examination of overt expressions, and of all that is bound up therewith, will go some way toward making superfluous the direct investigation of the structures of acts, indeed that there is a a subservience of descriptions of mental episodes to descriptions of what is public or overt. Even then, however, it would be important to understand the precise nature of the ontological relations between mental acts and overt utterances, and an examination of Wittgenstein's work very soon reveals that - in marked contrast to Husserl - he simply does not have the theoretical resources available to establish what these relations might be. He was thereby constrained, like Frege before him, and like the formal semanticists whom he attacked, to adopt an unrealistic position to the effect that mental acts are somehow incidental epiphenomena, superfluous shadows, lacking in cognitive value or theoretical relevance.

Now there are, trivially, three alternatives regarding the dependence relations between mental acts and overt or public linguistic behaviour: (I) the former are one-sidedly dependent on the latter, (II) the latter is dependent on the former, (III) the two are mutually dependent on each other.

(I) is clearly unacceptable (one need only try to imagine what it would be like to have uses of language without mental acts); yet this seems to be what is involved in the extreme thesis to the effect that mental acts are merely derivative epiphenomena.
(II) implies the Cartesian thesis according to which language is dispensable (is a mere 'clothing of thought'). Consider Hans, who is alone in his room, thinking hard about whether or not Erna really loves him. Hans arrives at a number of conclusions which he considers, rejects, and so on. In Hans's judgments Erna occurs again and again, different predicates are attributed to her in succession, now in memory, now in imagination. Do we not have here a freedom of variation of Hans's mental acts with respect to the level of overt expression? Certainly what Hans thinks is independent of what he would say were he to communicate his judgments to, say, his brother Otto. But does this imply that language is a mere 'dispensable clothing'?

More careful consideration shows that Hans's thoughts are in fact only locally independent of linguistic utterances. All of these silent judgings are still globally dependent on language in the sense that they are of such a complexity that they could not occur unless language existed (unless the facility existed in Hans to use the expressions of a natural language and to manifest this facility in overt actions). It is this fact, also, which explains why there is a subservience of descriptions of mental episodes to descriptions of what is public or overt. ${ }^{18}$

Which leaves us with (III). Language is clearly dependent on thought, or rather on mental acts in general, since there can be no learning of language (and no communication at all) without e.g. the exercise of associated perceptions. And thought is also dependent on language in the (global) sense just mentioned. This two-sided dependence is first of all a developmental thesis: language cannot be learned except against a background which includes, e.g., acts of perception. But more: it seems that, beyond a certain threshold of complexity, mental acts cannot occur except against a simultaneously existing background which involves linguistic habits and skills which have been inculcated publicly (habits and skills which will of course manifest dependence relations of their own, on different levels). This gives rise to a further set of problems for an ontology of language, problems having to do with the relations between the mental and the social.

\section{Against Cartesianism}

The present paper, for all its talk of acts, is not an exercise in Husserlian phenomenology, i.e. in the description of those parts or moments of acts that are transparent to their subjects. Our use of 'act' differs essentially from the favoured use of the later Husserl, who 
excludes from the notion of an act any 'extra-experiential' or 'non-phenomenological' elements that may be connected with them. By an act Husserl means just that component of an intentional event of consciousness that the subject himself can discern by 'reflecting' on his experience, excluding empirical facts about the intended cen by 'reflecting' on his experience, excluding empirical facts about the intended object and its de facto relation to the subject. Hence, an act is just what we might call the 'experiential' component of an intentional event, 'purified' (as Husser says) of presumptions concerning its 'interlacing with nature' (Woodruff Smith \& McIntyre 1982: 3).

One principal thesis of the paper - which finds support both in the realist critique of Husserl's transcendental phenomenology (as expressed e.g. in the writings of Ingarden) and also in more recent work by analytic philosophers on singular reference, indexicality, de re belief, de re perception and the like (see e.g. Evans 1982 and Woodfield 1982) - is that this Cartesian approach to the structures of acts is radically misconceived. Acts are simply one further variety of individual entity, existing in the real world along with substances, processes, states and events of other kinds. ${ }^{19}$ Acts differ from most other real entities in the fact that we can have some privileged or 'inner' access to them. But, this access is (almost always?) partial. And the fact that it is available should not blind us to the fact that, as real events in the spatio-temporal world, acts are susceptible also to various sorts of objective or public access including access via our linguistic expressions - making possible a description of their ontological structure in a way which is no different, in principle, from that which can be provided for entities of other sorts.

Cartesian assumptions remain powerful in contemporary philosophy however, for example in the form in which they have been revived by Fodor as the doctrine of 'methodological solipsism' (see Fodor 1981). It will thus be useful to underline why it is that they lead their proponents astray. Such assumptions may be summarised in the two-fold thesis to the effect that

(i) each individual human consciousness has a privileged access to his own mental phenomena;

(ii) the mental phenomena of each individual subject constitute a self-contained domain, somehow effectively isolable from the order of nature in such a way that our mental experience in its entirety would be exactly as it is even though the external world did not exist.

The idea that each consciousness has a privileged access to his own acts can be challenged on a number of fronts. It corresponds linguistically to the idea that mental verbs should be glossed as opaque in all occurrences of use (cf. Husserl 1984, §§ 4f.; Simons 1983). Yet the normal or unmarked sense of such verbs is transparent, the opaque sense requiring a special setting, such as the report of a psychiatric patient or dream-teller or vision-seer, this report and its evaluation being indepen- dent of the existence or otherwise of a corresponding referent. (One such special setting is provided by the philosophical activity known as descriptive phenomenology.) Further, the opaque reading of a mental verb must be parasitic on the transparent reading: for when such a verb is interpreted in the opaque sense, the associated object-clause is read as giving an account of what the subject is aware of in the relevant experience indirectly: by seeming to give a description of an object, the transparent experience of which by a normal subject would involve him in having experiences relevantly similar to the subject in question.

The second component in the assumption of Cartesianism has been challenged above all by Wittgenstein. Wittgenstein rejects the idea that there is a discriminable totality of all of that to which the subject has 'inner' access on the grounds that our ability to find our way around the parts of such a totality would of necessity depend upon capacities acquired whilst moving in the domain of what is publicly accessible. There is no way, he insists, in which a self-contained stratum of 'consciousness' could be carved out from the plethora of forms of interaction, both active and passive, overt and covert, of a human being with its animate and inanimate environment. And from this it follows that any putative classifications of private objects must obscure at least some important structural traits of the phenomena to be described.

Both our mental life and our overt actions rest on expressed and unexpressed habits and traditions, acquired above all through education and upbringing and through our experiences of the actions of others (including actions of correction and constraint provoked by our own overt behaviour). It is this background of shared traditions which makes our mental life, and our own understanding of our mental life, possible. By shaping and determining our overt utterances it thereby indirectly shapes and determines the repertoire of types of act which we have at our disposal, and at the same time ensures that the deployment of this repertoire is to a large extent a matter of ingrained reflex - or at least a matter over which we have only very fragmentary conscious control. Thus even the mental acts which occur are not such that they admit of any transparent access.

It will be clear, again, that such Wittgensteinian arguments should not be seen as implying that there are no mental acts. Wittgenstein has shown only that a totality of mental acts cannot be separated out from its surroundings, and above all that such a totality cannot be separated out from the public domain constituted by the actions, and especially the speech actions, in which we engage. But what cannot be separated out, what does not exist independently of its surroundings, does not thereby lose its claim to exist. One of the presuppositions of Wittgenstein's 
philosophy is precisely that there is no such thing as a dependent or non-separable existent. For if it made sense to distinguish between independent and dependent existents then it would make sense to talk of things having an a priori order, and this is something that Wittgenstein denies again and again throughout his work. ${ }^{20}$

\section{Husserl's Noema Theory of Meaning}

Sometime after the publication of the Logical Investigations, Husserl himself abandoned the theory of linguistic meaning as species and introduced a new view of meanings as special abstract entities, which he called noemata.

Anglo-Saxon readers of Husserl - indeed almost all his commentators - have interpreted his development from the Investigations to the Ideas in a way which takes for granted that the teleology which Husserl himself retrospectively inscribed upon his changes of mind - his 'development' - has some basis in the facts themselves. Thus it has been assumed that Husserl's rejection of the theory of meaning as species in favour of the theory of meaning as noema was somehow justified. This assumption seems, however, to be supported only by appeal to what Husserl himself has to say about the matter (after he has already given up the earlier position), and by the presence of a number of peripheral, if intriguing, similarities between the noema theory and the theory of Sinne developed by Frege in his "Über Sinn und Bedeutung". It is nevertheless interesting to spend some time examining the later theory, particularly in the refined form it has been given by Føllesdal, McIntyre and Woodruff Smith, since this may be said to combine many of the benefits of the language-based approach with a framework within which mental acts are capable of being taken seriously. ${ }^{21}$

On Husserl's earlier (species) theory, if Erna understands what Hans says, then this is because Hans's and Erna's thoughts are instances of the same species (at some level of generality), a fact which is itself to be understood in terms of certain kinds of constancy (similarity of parts) in the space of mental acts - constancy which has come about through a certain historical process (Hans and Erna share the same background of habits and skills). On the later (noema) theory no such historical account is possible, for we are dealing not with constancy amidst real variation, but with abstract meaning-entities outside space and time. Hans succeeds in communicating with Erna, on this account, because the meaning of his utterance, a certain abstract noematic Sinn, becomes the meaning of Erna's act of registering this utterance. It is as if the noema- tic Sinne are stars in an abstract heaven to which our successive acts, and even the successive acts of distinct subjects, may - somehow - be identically directed.

So far, so Fregean.

Husserl's noema theory can be said to be superior to Frege's in at least one respect however. For Husserl provides an account of the noemata or Sinne of all acts: perceptual, imaginative, judgmental, etc., where Frege can cope only with judgmental acts, or more specifically with the language bound up with specific sorts of judgmental act. This is an important advantage, since if we want to deal, e.g., with indexical uses of language ('That bird is flying high'), we shall find it necessary to recognise that the relevant utterances can be meaningful only if they occur as parts of larger wholes which include acts of perception directed toward non-linguistic objects. ${ }^{22}$ In this very advantage of Husserl's later theory lies a danger however. For the structure and individuation conditions of abstract noemata are essentially derived from our understanding of the logical structures of corresponding linguistic expressions. (This, surely, is the central message of the new 'Frege-Husserl semantics'.) If, therefore, we insist that abstract noemata are such as to exhaust the meanings also of perceptual acts, then we would seem to be trying to bring into coincidence two entirely different sorts of structure - having different sorts of multiplicity. For the structures of linguistic meanings are discrete, subject to those sorts of non-continuous variation which come about through the divisions and combinations dictated e.g. by the rules of syntax. The structures of perceptual contents, in contrast, are continuously variable along a number of qualitatively highly specific dimensions, in a way which implies that it is impossible that there could ever be a fitting together of the two of the sort that is required by the newly fashionable interpretations of Husserl's later theory.

The earlier theory, on the other hand, which draws a sharp line between the two sorts of content, is subject to no such danger. And in other respects, too, the comparison between Husserl's own successive theories of meaning is not at all to the disadvantage of the former. Indeed neither in Husserl, nor in contemporary proponents of the noema, is any argument given for favouring the later theory rather than the earlier. This is true not least because the earlier theory is not, in any of the secondary literature, worked out in detail. ${ }^{23}$

When Husserl's two successive theories are compared, we see a number of advantages of the former. This is so, first of all, in regard to their respective ontological commitments. Both theories accept the need for mental acts as real events (in the later theory these are called 'noeses'). Further, both accept the need for some account of generality. In- 
deed the later theory distinguishes (and this is just for starters): the noematic Sinn of an act, the matter of the act which 'entertains' this Sinn (a certain real moment), the essence or species of this matter, and in principle also the essence or species of the noematic Sinn. ${ }^{24}$ The earlier theory, in contrast, has only acts (certain real events), their parts, and the species these instantiate, and we have seen that even the latter need not, of necessity, be taken ontologically seriously.

Further, the relations of species to instance and of part to whole to which the early theory appeals are well understood. The later theory, in contrast, needs relations capable of embracing as their relata both abstract and concrete entities (as if such heterogeneous entities could be capable of being combined together within a single whole). As Woodruff Smith and McIntyre inadvertantly reveal, ${ }^{25}$ the intermediary role of abstract noemata saddles us with two insoluble problems:

(i) the problem of entertaining, i.e. the problem of the relation of the noema to concrete mental episodes. (How can a real mental event exist together with an abstract noema/Sinn within a single whole?)

(ii) the problem of anchorage, i.e. the problem of the relation of the noema to concrete objects. (How can a mental act, in somehow grasping an abstract noema, thereby be directed or referred e.g. to a concrete thing?)

Woodruff Smith and McIntyre's own suggested solution to the first of these two problems operates at the level of metaphor. An act, they say,

intends (is directed toward or is intentionally related to) an object if and only if the act (or its noesis) entertains a certain noematic Sinn and that Sinn prescribes that object (WS \& M: 143).

But what is this 'entertaining', which appears to be a peculiar sort of non-intentional intentionality? ${ }^{26}$ It seems, indeed, that the word 'entertains' can elucidate nothing. It merely recalls an exactly parallel problem in the interpretation of Fregean philosophy, the problem of giving an account of the relation of Fassen between an act of thinking and a Fregean Gedanke (cf. Willard 1984: $180 \mathrm{ff}$.). ${ }^{27}$ It is perhaps significant that Woodruff Smith and McIntyre find no further analysis of entertaining in Husserl's own writings. Rather than accepting this as sufficient evidence of a major flaw, either in their interpretation of Husserl's theory or in the theory itself - that perhaps a view of the relation between act and meaning along the lines of the earlier theory might be right after all - they take refuge behind a set-theoretical analysis of 'entertaining', conceiving it as a 'many-one or functional relation' (WS \& M: 146). But the rigmarole of functions across possible worlds which they wheel forth in order to support this view (cf. their chs. 6 and 7) yields (at best) nothing more than a rather shaky structural analogy; it does not tell us what the ontological status of these peculiar abstracta and of the associated relations might conceivably be.

In regard to the problem of anchorage, Husserl himself was ultimately to by-pass this problem by abandoning the attempt to establish contact between noema and world (the insidious pressure of the noema theory in the direction of 'transcendental idealism'). For it seems that the noema theory is unable to specify which objects acts are directed towards. Noemata are abstract entities (they are rather like the 'concepts' of old). In no sense are they tied up with or sensitive to the concrete and individual spatio-temporal entities which (as we normally conceive things) people the world of our experience. Thus the noema theorist has no way to distinguish, say, thinking-about-McIntyre from thinkingabout-some-philosopher-qualitatively-indistinguishable-from-McIntyre. To succeed in describing a particular person's thinking-about-McIntyre (his being minded in just this way), we need to recognise that his acts, and their background, are tied to a certain segment of reality (that they are one-sidedly dependent upon certain objects, in the sense of our discussion above ${ }^{28}$ ).

Something similar holds even where there is no object of our act, e.g. where we are thinking (as we conceive things) about the god Jupiter. For here, too, there is a problem of anchorage: even our acts of thinkingabout-Jupiter need to be distinguished from acts of thinking-aboutsome-god-qualitatively-identical-with-Jupiter, and to this end they must be tied into a certain complex background which includes ancient Mediterranean peoples, their religious beliefs, traditions and practices, and the remnants and reports which survive in various media and inform us of these. ${ }^{29}$ This is another dimension in which Husserlian phenomenology is inadequate to the ontology of acts: it fails to do justice to this background, which exists in virtue of a network of foundation relations between any given act and the objects of prior acts with which it is associated.

The response of the noema-theorist is to seek to simulate this mundane background by complicating his account of the mutual interrelations among acts, by appealing to what is called the act's horizon (Ideas I § 149).

The clearest account of this matter is provided by Woodruff Smith and McIntyre in their ch. 5. Every act, they tell us, has a horizon, fixed by specific components of the act's Sinn together with parts of the subject's conceptual scheme or belief-system. Now it is of course reasonable to seek to extend the phenomenology of the act by recognising a role for 
background beliefs, even those background beliefs that are not "active" phenomena of consciousness in the way the act itself is (WS \& M: 254). We could see this background as somehow latent in an act, present in it "in the form of a habitus" (EU $\S 25$, cf. also $\S 67 \mathrm{~b}$ ). The Husserl of 'horizons' and 'noemata' is not, however, operating with real events and states and with their real cumulation through time, nor with that background of knowledge that is actually acquired in our past experience. He is operating, rather, with peculiar non-actual dispositions. ${ }^{30}$ Thus he sees an act's horizon as consisting of various possible acts, in which the object of the initial act would be intended under various further aspects, with details filled in about (say) those sides of the object that are originally hidden from view (WS \& M: 239). The horizon of an act of perception, for example, would consist of perceptions the perceiver could have had in the past (and indeed in the future also) (WS \& M: 259). The noematic Sinne of these merely possible components of the horizon are then held, as if by magic, to contribute to determining which object the act is directed towards:

The complete 'meaning' of an individuative act, as we have described it, typically includes not only the Sinn that is actually and 'explicitly' present in the act,...but also the system of Sinne correlated with certain related background beliefs. A complete phenomenological analysis of the act must embrace those Sinne as well cause it is [they] that ultimately prescribe which individual the act is directed toward or is about. (WS \& M: 390)

The problem of objective reference is hereby however shunted off into a corner of dark 'potentialities'. Not only is this appeal subject to the objection that it is an account of what is real in terms of what is merely possible. Even on its own terms it is not adequate to do the job which it has set itself: no account of the phenomenology of a person's acts, not even when the implicit or latent 'horizon' of these acts is taken into account, not even when their various 'sedimentations' are taken into account, can ensure for these acts the appropriate referent. For again, even the complicated horizonal background could in principle occur elsewhere, e.g. on Putnam's twin-earth. To anchor putative reference to 'our' Jupiter and his background as distinct from twin-Jupiter and his background we need an indispensable relational element, and this means breaking out of the phenomenological circle and taking the acts of the subject in their natural setting, intervolved in manifold ways with the rest of the natural world.

\section{NOTES}

1) I should like to thank the Alexander von Humboldt Stiftung for the award of a grant for research in Louvain and Erlangen where this paper was written. It owes a great deal to Kevin Mulligan, and grew out of a collaboration with him on the essays - Mulligan \& Smith 1986a and $1986 \mathrm{~b}$ - listed in the bibliography below. Thanks are due also to Karl Schuhmann for helpful comments.

2) Assuming, of course, that it has an object.

3) I shall concentrate in what follows on empirical uses of sentences in a natural setting, sentences for which it seems reasonable to assume that some truth-maker exists. See Mulligan, Simons \& Smith 1984.

4) See especially pp. 20-27, 88-103 of Brentano 1982 and also Mulligan \& Smith 1985 for a discussion in English.

5) See e.g. LU II § 3. The real parts in question are sometimes called by Brentano and Husserl 'logical parts': see Brentano 1982 (p. 20), Mulligan and Smith 1985, and LU III $\S \S 1 \mathrm{f}$

6) See also, more lately, Prior 1949 and Searle 1959. The fact that Husserl's understanding of logic and ontology and of form and matter rests on the assumption of the tree-structure of species is evident from his repeated discussions e.g. of lowest species and differentiae, of species and genera, of ideal singulars, etc. See e.g. LU "Prolegomena" $\S \S$ 46, 70; I $\S 31,33$; II § 26; III $\S \S 7 a, 10 f$., 16, 22; IV § 7; V \& 26. Compare also Husserl's 46,70 ; I $\S 31,33$; II $\S 26$; III $\S \S 7 \mathrm{a}, 10 f ., 16,22$; IV $\S 7$; V $\S 26$. Compare also Husserl's
letter to Lipps of Jan. 1904 (Schuhmann 1977), and Willard 1984 (e.g., p. 64). That this background of Aristotelian ontology was important to Husserl is clear also from the first chapter of the first book of the Ideen - and we can conjecture that he included this extensive treatment of the Aristotelian theory of generality precisely because he was concerned by the lack of understanding of his intentions in the earlier work.

7) Thus in LU III \& 14 Husserl refers to "the great scientific interest that the constitution of a deductive theoretical transformation claims in every field". "Nothing can show up the value of an exact determination more clearly than the possibility of giving a deductive proof of such propositions as are familiar to us in a different guise." (Emphasis mine.) The theoretical interest of the idea of dependence derives also from the fact that, as Husserl has shown, it can contribute to the understanding of a range of other central formal ontological notions. The work of Ingarden (1964-65) suggests further that by distinguishing between different notions of dependence one can produce a theory of great power in the domain of general metaphysics.

8) See the works by Mulligan, Simons and Smith (and aggregates thereof) in the list of references below.

9) For references see Mel'čuk 1979, Schachter 1980.

10) See Mulligan (forthcoming b.) and also Smith 1986a and 1986b for further details.

11) On act-based theories of meaning in general and on Husserl's theory in particular see Smith 1986a.

12) This account applies strictly speaking only to what Husserl calls objectifying acts, but since all other acts - for example episodic emotional phenomena - are themselves one-sidedly founded on objectifying acts, the matter-quality-intuitive content distinction is in effect inherited by these also. Cf. LU V $\S 41$.

13) Husserl's distinction between quality and matter had its origins in the distinction between act, content, and object first clearly formulated by Twardowski 1894. The opposition between the content and object of an act is in its turn often compared with Frege's opposition between the sense and reference of an expression. It is necessary to emphasise 
already here, however, that the matter of an act as Husserl understands it in the LU cannot be equated with any abstract entity (e.g. with a 'proposition' or a Sinn). For act matters are real, individual parts of mental events; abstract entities, in contrast (if they exist at ters are real, individual parts of men
all), are outside space and time.

14) Compare the account of noticing put forward by Brentano (1982: 31-64; see also Wenning (forthcoming) and Stephens 1978: 138f). Clearly not all complexity in the object of perception is mirrored by a corresponding complexity of the act.

15) The 'roughly' is inserted here in order to draw attention to the fact that not all parts and moments of those concrete mental events through which uses of language get their meaning are relevant to this meaning. For further details see Smith 1986b.

16) Some philosophers have even gone so far as to impose a sentential form upon simple acts of perception (such that my seeing the on-coming fist is already a 'disguised judgment'): see Mulligan, Simons \& Smith 1984. The view that perceiving is propositional is not an invention of analytic philosophers - there may be traces of the idea even in Hume and the first major attack on the idea is in Husserl's fifth Logical Investigation.

17) See also Russell's Analysis of Mind, where acts are dispensed with in a contex which involves explicit reference to Brentano and Meinong.

18) This distinction between global and local independence, as also the arguments for its employment in this case, are due to Kevin Mulligan.

19) See Mulligan \& Smith 1986b, for a more detailed elaboration of this thesis.

20) See, e.g., Tractatus 5.634, Zettel, \& 357. The line of thinking in the present paragraph owes a lot to discussions with Kevin Mulligan.

21) I shall concentrate in what follows on Woodruff Smith and McIntyre's book of 1982 (abbreviated as WS \& M). The book is an excellent example of Husserlian thought of the sort that has been sadly lacking since the heyday of phenomenology in the early years of the century, and I am grateful to its authors for useful discussions of its content. I hope that no apology is needed for the somewhat critical tone of my treatment, for I have of course passed over in silence those points in the book with which $I$ am in agreement.

22) See Mulligan \& Smith 1986a. It was above all Karl Bühler who developed Husserl's ideas in the direction of a general theory of indexicality: see Mulligan (forthcoming a.).

23) A single, noble exception to this general trend is the work of Dallas Willard, above all his 1972 and 1984. See also Hoche 1973 (p. 203), and Küng 1976, who give textual evidence that Husserl very belatedly entertained the view that his position at the time of the LU was possibly right after all.

24) For a fuller account - minus the dimension of essence or species - see the diagram on p. 136 of Woodruff Smith and McIntyre's book.

25) Cf. their diagram on p. 143 .

26) Thus we are told for example that entertaining a Sinn 'does not require any explicit awareness of the Sinn by the subject who so entertains it' (p. 144).

27) The metaphor of entertaining recalls also the central weakness in once popular accounts of belief and other 'propositional attitudes' as a matter of a believer's being directed towards an abstract 'proposition'.

28) See Smith 1984 for a view along these lines.

29) I am grateful to Peter Simons for this point: see his 1983

30) Woodruff Smith and McIntyre sometimes suggest further that these horizons are like noemata in being abstract entities, which would imply that they were entirely outside the temporal domain of what happens and is the case. I shall ignore this question here.

\section{REFERENCES}

Brentano, Franz. 1924-25. Psychologie vom empirischen Standpunkt. 2nd ed., 2 vols. Leipzig: Meiner. (Engl. transl., Psychology from an Empirical Standpoint. London: Routledge, 1973.)

- - 1982. Deskriptive Psychologie. Ed. by Roderick M. Chisholm \& W. Baumgartner. Hamburg: Meiner.

Dreyfus, Hubert L. ed. 1982. Husserl, Intentionality and Cognitive Science. Cambridge, Mass.: MIT Press.

Eschbach, Achim ed. Forthcoming. Karl Bühler's Theory of Language (=Viennese Heritage, 2.) Amsterdam: John Benjamins.

Evans, Gareth. 1982. The Varieties of Reference. Ed. by John McDowell. Oxford: Clarendon.

Fodor, Jerry: 1981. "Methodological Solipsism as a Research Strategy in Cognitive Psychology". Dreyfus 1982. 277-303.

Hoche, H.-U. 1973. Handlung, Bewußtsein und Leib. Freiburg: Alber. - .1982 . "Beziehungen zwischen der Semantik Freges und der Noematik Husserls". Archiv für die Geschichte der Philosophie 64. 16697.

Holenstein, Elmar. 1976. Roman Jakobson's Approach to Language: Phenomenological structuralism. Bloomington \& London: Indiana Univ. Press.

Hudson, Richard A. 1976. Arguments for a Non-transformational Grammar. Chicago \& London: Univ. of Chicago Press.

- - 1984. Word Grammar. Oxford: Blackwell.

Husserl, Edmund. 1894. "Intentionale Gegenstände". Ms. first published in Husserl 1979, 303-48.

- - $\mathrm{LU}=1900-01$. Logische Untersuchungen. 1st ed. Halle: Niemeyer. 2nd ed. 1913-22. [Both editions repr. as Husserliana, XVIII, XIX.] (Engl. transl. of 2nd ed. by John Niemayer Findlay, Logical Investigations. London: Routledge, 1970.)

- 1913. Ideen zu einer reinen Phänomenologie und phänomenologischen Philosophie. I. Buch: Allgemeine Einführung in die Phänomenologie. Halle: Niemeyer. [Repr. as Husserliana, III, 1.]

- $. \mathrm{EU}=1947$. Erfahrung und Urteil: Untersuchungen zur Genealogie der Logik. Hamburg: Claassen and Goverts. (Engl. transl., Experience and Judgment by J.S. Churchill and K. Ameriks. London: Routledge, 1973.)

- 1979. Aufsätze and Rezensionen 1890-1910. Ed. by B. Rang. (= Husserliana, XXII.) Haag: Nijhoff.

Ingarden, Roman. 1964-65. Der Streit um die Existenz der Welt. 2 vols., 
the second in 2 parts. Tübingen: Niemeyer. Partial Engl. transl. of vol. I as Time and Modes of Being. Springfield: Thomas, 1964.

Küng, Guido. 1976. "Das Noema als reelles Moment". Phenomenological Perspectives ed. by P.J. Bossert, 151-53. The Hague: Nijhoff.

Mel'čuk, A.I. 1979. Studies in Dependency Syntax (Linguistica Extranea, 2) ed. by P.T. Roberge. Ann Arbor: Karoma.

Mulligan, Kevin. Forthcoming a. "On Bühler's Examples". Eschbach, forthcoming.

Mulligan, Kevin ed. Forthcoming b. Speech Act and Sachverhalt. Reinach and the Foundations of Realist Phenomenology. Dordrecht: Nijhoff.

Mulligan, Kevin, Simons, Peter M. \& Smith, Barry. 1984. "TruthMakers". Philosophy and Phenomenological Research 44. 287-321.

Mulligan, Kevin \& Smith, Barry. 1985. "Franz Brentano and the Ontology of Mind". Philosophy and Phenomenological Research, 45, 62744.

- 1986a. "A Husserlian Theory of Indexicality", Grazer Philosophische Studien, 27 (forthcoming).

- . 1986b. "A Relational Theory of the Act", Topoi, forthcoming.

Prior, Arthur N. 1949. "Determinables, Determinates and Determinants". Mind 58. 1-20, 178-94.

Putnam, Hilary. 1975. "The Meaning of 'Meaning"'. Language, Mind and Knowledge (=Minnesota Studies in the Philosophy of Science, 7). 131-93. (Repr. in Putnam, Philosophical Papers, vol. 2, Mind, Language and Reality. Cambridge: Cambridge Univ. Press 1975.)

Reinach, Adolf. 1913. "Die apriorischen Grundlagen des bürgerlichen Rechts". Jahrbuch für Philosophie und phänomenologische Forschung 1. 685-874. (= Reinach 1921, pp. 166-350.) (Engl. transl. by J.F. Crosby, "The A Priori Foundations of the Civil Law". Aletheia 3. 1-142 (1983).)

- 1921. Gesammelte Schriften. Halle: Niemeyer. (New edition, ed. by Karl Schuhmann \& Barry Smith, Munich: Philosophia, forthcoming.)

Russell, Bertrand. 1921. The Analysis of Mind. London: George Allen \& Unwin.

Schachter, P. 1980. "Daughter-Dependency Grammar". Current Approaches to Syntax (= Syntax and Semantics, 13) ed. by E.A. Moravcsik and J.R. Wirth, 267-99. New York: Academic Press.

Schuhmann, Karl. 1977. "Ein Brief Husserls an Theodor Lipps". Tijdschrift voor Philosophie 39. 141-50.

Searle, John R. 1959. "Determinables and the Notion of Resemblance". Proceedings of the Aristotelian Society, Supplementary Volume 33. 141-58.
Simons, Peter M. 1983. "Contents and Objects". Epistemology and Philosophy of Science ed. by P. Weingartner and H. Czermak, 81-84. Vienna: Hölder-Pichler-Tempsky.

Smith, Barry. 1984. "Acta cum fundamentis in re". Dialectica 38. 15778.

- - 1986a. "Materials Towards a History of Speech Act Theory". Eschbach, forthcoming.

- - 1986b. "Ten Conditions on a Theory of Speech Acts". Theoretical Linguistics, 11, 311-30 (issue dated 1984).

- - 1986c. "Logic and Formal Ontology". Husserl: An Introductory Survey of His Thought ed. by Jitendranath Mohanty \& W. McKenna. Lanham: University Press of America.

Smith, Barry ed. 1982. Parts and Moments: Studies in logic and formal ontology. Munich: Philosophia.

Smith, Barry \& Mulligan, Kevin. 1982. "Pieces of a Theory". Smith 1982. 15-109.

- - 1983. "Framework for Formal Ontology". Topoi 2. 73-85.

Stephens, J.W. 1978. Phenomenology and Realism: An Essay on Husserl's 'Logical Investigations". Diss. Univ. Princeton.

Stumpf, Carl. 1873. Über den psychologischen Ursprung der Raumvorstellung. Leipzig: Barth.

Twardowski, Kazimierz. 1894. Zur Lehre vom Inhalt and Gegenstand der Vorstellung: Eine psychologische Untersuchung. Vienna: Hölder. (Repr. Munich: Philosophia, 1983. Engl. transl. On the Content and Object of Presentations, by R. Grossmann. Haag: Nijhoff, 1977.)

Wenning, W. Forthcoming. "Remarks on Marty on Colour". Mind, Meaning and Metaphysics: The philosophy and theory of language of Anton Marty ed. by Kevin Mulligan. Dordrecht: Nijhoff.

Willard, Dallas. 1972. "The Paradox of Logical Psychologism: Husserl's Way Out". American Philosophical Quarterly 19. 94-100. (Repr. in Husserl: Expositions and appraisals. ed. by F. Elliston and P. McCormick, 10-17. Notre Dame: Univ. of Notre Dame Press, 1977.)

- - 1984. Logic and the Objectivity of Knowledge: A study on Husserl's early philosophy. Athens, Ohio: Ohio Univ. Press.

Woodfield, Andrew ed. 1982. Thought and Object: Essays on intentionality. Oxford: Clarendon.

Woodruff Smith, D. \& McIntyre, R. 1982. Husserl and Intentionality. Dordrecht: Reidel. 